World Journal of Educational Research

\title{
Factors Effecting on Study Habits
}

\author{
Zebun Nisa Khan ${ }^{1 *}$ \\ ${ }^{1}$ Associate Professor, Department of Education, AMU Aligarh, India \\ *Zebun Nisa Khan, E-mail: zebunnisakhan@yahoo.com
}

\begin{abstract}
The present study was undertaken with the objectives to find out the impact of Socio-economic Status as well as sex differences on study habits of class VII students (100) of Government Colleges of Amroha District. The effects of two independent variables on study habits of the aforementioned students were assessed by using two Psychological tests namely Socio-economic Status Scale (Urban); by Dr. Kulshrestha and Rao's Study Habits Inventory. The findings indicated a significant effect of gender on study habits of the subjects. The effect of Socio-economic Status on study habits was found to be insignificant. Interaction effect of sex difference and Socio-economic Status was also not significant.
\end{abstract}

\section{Keywords}

study habits, academic performance, educational achievement, socio-economic status, motivation, academic neuroticism

\section{Introduction}

Study habits are termed as the methods of study of students. Study habits are student's ways of studying whether systematic, efficient or inefficient (Ayodele \& Adebiyi, 2013) implying that efficient study habits produces positive academic performance while inefficient study habits leads to academic failure. Socio-Economic Status (SES) of parents and the education agencies play a vital role in molding the study habits of the students at all levels of education. Plowden (1967) revealed that when both parents and teachers provide the support system needed to guide their child's growth, the child has a greater chance for educational achievement. The study habits, with proper environment, feedback and guidance help the individual to develop a balanced personality. In school, the teachers while at their home the parents should guide the student for his/her study habits. Thus, it is the duty of the teachers and parents to identify student's good study habits and guide them accordingly. The study habits and Socio-economic Status of an individual go hand in hand. They may be regarded as the two faces of the same coin; they are proportional to each other. If either of these factors is absent or has been lacking, it leads to an incomplete personality development of an individual. The individual constantly evaluates himself/herself in relation to his/her society. These evaluations are derived from "the values of the significant others ... (which) constitute the mirrors in which individual see their self-image and reach self-appraisals". Individual's success in social status accompanied by the evaluative responses by others of the social groups has a high reward value to the person. Though, the children are not by themselves expected to attain the 
status/which fetches favorable reaction from others, they share the benefits and privileges that their parents enjoy in the social class. Study habits are well planned and deliberate pattern of study which has attained a form of consistency on the part of the students towards understanding academic subjects and passing the examination (Bashir \& Mattoo, 2012). Good study habits and environment should prevail among the schools, and school students are continuously faced with the problem of mass failure, poor school grades and incessant repetitions, and thus subsequent withdrawals from school. This poor performance may be due to poor study habits and the lower Socio-economic conditions in which they live. Weak study habits of the student effects the academic performance drastically. Improvement of study habits of the students is necessary so that they perform well in their studies. Bajwa and Jindail (2005) concluded that there is significant difference between high Socio-economic Status and low Socio-economic Status on the variable of under achievement. Bhan and Gupta (2010) examined study habits and academic achievement among the students belonging to Schedule Caste and non-Schedule Caste group. The result revealed that sex has no significant impact on the academic achievement of students.

Education is the most important invention of mankind, it has a very wide meaning and it is not possible to give it a precise meaning. Different philosophers and scholars have defined education according to their own ideas and philosophies. Education helps an individual to give his/her identity. It is not limited to four walls of the classroom, but also outside in the environment. Education begins from womb and ends with the death of an individual.

An individual may have good Socio-economic Status, but when he/she does not have proper guidance for study habits, and then the proper education remains unexposed. It has been thought that there is relationship between a student's academic achievement and their study habits (Febregat \& Blanch, 2004). Fielden (2004) stated that a good study habits have good effects towards the academic performance of the student. Gellinger and Seibert (2002) noted a link between poor study habits and low academic achievement in that student with poor study habits tends to have poor achievements. Study habits effects and increase the efficiency of the students with respect to his/her academic achievement. Thus study habits and Socio-economic Status have great impact throughout the life of an individual. In the light of the above discussion, the present study was designed to investigate the influence of Socio-economic Status and sex differences on study habits of school students.

\section{Objectives}

In specific terms the study aims to:

1) Study the impact of Socio-economic Status of school students on their study habits.

2) Examine the impact of sex difference on the study habits of the subjects.

3) Investigate the interaction effect of sex differences and Socio-economic Status on study habits. 


\section{Sample}

The population of the current study included all boys and girls attended at Government Girls and Government Boys schools of Amroha District U.P., India for class VII in the year 2014-2015. 100 Students selected as a sample size in this study. Random sampling was utilized for the study. By using table of random numbers, 50 boys and 50 girls were chosen. The sample was further split on the basis of high and low Socio-economic Status.

\section{Tools}

The following instruments were used to collect data:

1) Socio-economic Status Scale (SES Scale Form A), Urban by Dr. S. P. Kulshrestha was used to select high SES and low SES subjects.

2) A standardized tool "Rao's Study Habits Inventory" was used. This inventory consists of 40 items covering the six dimensions of study habits.

a) Planning; b) Effective reading habits; c) Note taking preparation and revision; d) Motivation \& interest; e) Concentration \& clarity; f) Academic neuroticism. The inventory is a Five Point Scale in Likert Format.

3) The data were analyzed with the help of statistical techniques computing means and F-ratios.

\section{Results and Discussion}

To find out the effect of SES on study habits the data were presented and analyzed in the form of Table 1 as follows:

Table 1. F-Ratios between Different Sex with High and Low SES

\begin{tabular}{llllll}
\hline Sample & Observation & Mean & Variance & df & F- ratio \\
\hline Boys with High SES & 25 & 38.74 & 23.5833 & 24 & \\
Girls with High SES & 25 & 36.87 & 19.7766 & 24 & 0.66977 \\
Boys with Low SES & 25 & 34.46 & 08.5933 & 24 & \\
Girls with Low SES & 25 & 25.12 & 29.2244 & 24 & 0.27040 \\
\hline
\end{tabular}

The objectives of the present investigation were to study the impact of Socio-economic Status and sex differences on study habits of the subjects. The data were analyzed with the help of suitably prepared computer programs at the general computer lab, A.M.U, Aligarh. A part of data was also treated manually.

The mean values indicate that both boys $(M=38.74)$ and girls $(M=36.87)$ of high SES have better Study habits than those from low SES boys $(M=34.46)$ and girls $(M=25.12)$. The results also depict that high SES boys have the highest mean score $(\mathrm{M}=38.74)$. 
To study the significant effect of sex differences (boys and girls) and SES (high and low) on study habits, 2x2 factorial design was used and F-ratios were calculated. F-ratios for sex differences were significant at 0.01 levels, which indicated that boys and girls differ significantly on study habits.

F-ratio for interaction effect of gender (Boys and Girls of High SES) is insignificant (0.66) which shows that two levels of SES are independent of the gender differences and study habits. The third hypothesis that there is no significant interaction effect of gender and SES on study habits of the subjects is, therefore, accepted and is supported by Jahan (1985) and Showkeen and Khan (2014).

F-ratio for SES was also insignificant (0.27) indicating that study habits were independent of SES effects. The second hypothesis that there was no significant effect of SES on the study habits of the subjects was therefore accepted, which is also supported by Showkeen and Khan (2014A, 2015). Today, parents (high or low SES) have generally become more conscious for the educational and all round development of their children. Parents of many low SES families work hard to send their children in good schools because they think that better educated children may get better employment and satisfaction in the life. The study habits of children satisfied in their peer group school and at their home are not affected by low SES of their families.

The present finding is in consonance with the findings of Khan (2002), Bajwa (2005) and Showkeen and Khan (2014, 2014A, 2015), which also found no significance differences regarding the study habits. The reason behind this may be having differences in child rearing practices between boy and girl child. In many Indian families, a boy gets more opportunities, encouragement and support for his development in comparison to his girl counterpart. The boy gets more outdoor opportunities while girl has to help in household work and to look after the siblings. All these factors affect the study habits of boy and girl differently.

\subsection{Major Findings}

The problem investigated was to explore the relationship between the study habits of the students of both the sex with high and low Socio-economic Status and academic achievements. The findings may be helpful for the parents and teachers to understand the importance of the study habits for the academic success. The current study found that:

1) Gender has a significant impact on the study habits.

2) Socio-economic Status does not significantly affect the study habits.

3) Two levels of Socio-economic Status (high and low) are independent of gender effect and study habits. Jointly, gender and Socio-economic Status do not significantly affect study habits.

Additional research needs to be conducted to confirm the above finding and to study that classroom attendance also influences the academic achievement of the student study habits to enhance. 


\section{Acknowledgement}

Author is thankful for the learned referee for his/her suggestions for the improvement of the paper.

\section{References}

Acheaw, M. O., \& Larson, A. G. (2014). Reading Habits among Students and its Effects on Academic Performance: A Study of Students of Koforidua Polytechnic. Library Philosophy and Practice (e-journal), 1130, 1-22. Retrieved from http:/www.digitalcommons.unl.edu/libphilprac

Ayodele, C. S., \& Adebiyi, D. R. (2013). Study Habits as Influence of Academic Performance of Students Nurses of Banquet State University. International Journal of Nursing Science, 5(2), 60-65.

Bajwa, S., \& Jindal, S. (2005). Under Achievement in Science in Relation to Intelligence and Socio-economic Status. Indian Journal of Psychometry and Education, 36(2), 142-145.

Bashir, I., \& Mattoo, N. H. (2012). A Study of Study Habits and Academic Performance Among Adolescents (14-19) Years. International Journal of Social Science Tomorrow, 1(5), 1-8.

Bhan, K. S., \& Gupta, R. (2010). Study Habits and Academic Achievement Among the Students Belonging to SC and None SC Groups. Journal of Applied Research in Education, 15(1), 1-9.

Fielden, K. (2004). Evaluating Critical Reflection for Post-graduate Students in Computing. Informing Science and Information Technology Education (Joint Conference 2005, Flagstaff, Arizona). Retrieved from http://www.informingscience.org/Proceedings/In SITE2005/138f36 Field.pdf

Isangedighi, A. J. (1997). A Comparison of Study Habits Among the Under Achieving, the Achieving and Over Achieving Junior Secondary Students. West African Journal of Educational Research, 1, 114-119.

Jahan, Q. (1985). A Study of Personality Profiles of Students of Science, Arts and Commerce at Higher Secondary Level of Education in Relation to their Academic Achievement (Ph.D. Thesis AMU Aligarh, India).

Khan, Z. N. (2002). Characteristics of High Achieving Girls in Science Stream at Higher Secondary Stage-a Factorial Study. Indian Journal of Psychometry and Education, 33(2).

Oluwatimilehin, J. T. B., \& Owoyele, J. W. (2012). Study Habits and Academic Achievement in Core Subjects among Junior Secondary School Students in Ondo State, Nigeria. Bulgarian Journal of Science and Education Policy, 6(1), 155-169. Retrieved from http://www.bjsep.org

Plowden, B. (1967). Children and their Primary Schools. A report of the Central Advisory Council for Education (England). London: Her Majesty’s Stationary Office.

Showkeen, B. W., \& Khan, Z. N. (2014). Assessment and Understanding of Gender Equity in Education in Jammu and Kashmir. Review of Literature, 1(6), 1-12.

Showkeen, B. W., \& Khan, Z. N. (2014). Gender Disparity at Elementary Education Level in Jammu and Kashmir: An Exploratory Study. European Academic Research, 2(9), 11778-11789.

Showkeen, B. W., \& Khan, Z. N. (2015). A Perceptual Study of Girls Education, its Factors and 
Challenges in South Kashmir. Asian Journal of Multi-disciplinary Studies, 3(1), 107-110.

Sukhwant, B., \& Shalu, J. (2005). Under Achievement in Science in relation to Intelligence and Socio-economic Status. Indian Journal of Psychometry and Education, 36(2), 142-145. 